\title{
Artificial Intelligence Role for Advertising Campaigns development
}

\author{
Omneya Sabry Riad Abdel Wanes ${ }^{\text {a }}$
}

a) Assistant Lecturer, Faculty of Fine Arts, Alexandria University, Egypt

\begin{abstract}
:
Our world is now incredibly fast-paced and bustling, making it increasingly difficult to get people's attention and get their attention. We deal with an abundance of news 24 hours a day, and social media platforms try to keep us on their platforms, surrounded by a barrage of e-mails and messages that never seem to be out. With all the noise, it is relatively surprising that companies can communicate their messages and communicate their offerings effectively to potential customers.
\end{abstract}

\section{$\underline{\text { Key Words }}$}

- Artificial intelligence

- Advertising campaigns

- Augmented Reality

- Marketing

\section{Introduction}

Our world is now incredibly fast-paced and bustling, making it increasingly difficult to get people's attention and get their attention. We deal with an abundance of news 24 hours a day, and social media platforms try to keep us on their platforms, surrounded by a barrage of e-mails and messages that never seem to be out. With all the noise, it is relatively surprising that companies can communicate their messages and communicate their offerings effectively to potential customers.

Thanks to the digital marketing revolution, we have a lot of data at our disposal from customer relationship management systems, marketing programs, advertising platforms, etc. But we lack the time, energy, or cognitive ability to effectively process all of this data, even though it likely holds insights that can greatly improve our campaigns. As a result, our marketing and advertising performance suffers, costing brands a lot of time and money. 
INTERNATIONAL JOURNAL OF

ARTIFICIAL INTELLIGENCE AND EMERGING

TECHNOLOGY

Also, as a result, entrepreneurs and future marketing leaders are turning to Al for its ability to increase revenue, reduce costs, and build a massive competitive advantage. Artificial intelligence solutions aiming to help identify potential customers, overly personalize and personalize messages according to their specific needs, improve ad placement, and identify the most effective means of communicating the message, which is a leap in this experience. In fact, Al is particularly good at all of these things: identifying leads through grouping and matching patterns, designing messages through Al-powered hyper-customization, and finding the best times and means to communicate by identifying patterns.

Advertising Al has the potential to increase your return on advertising (revenue) and reduce the amount you spend on employee time and ineffective advertising budget.

\section{Research Challenges:}

Among the most important questions of the research challenges to deal with: What are the advanced methods of advertising methods that enable companies to create advertising campaigns? And to what extent can artificial intelligence be used in media advertising campaigns? What is the extent of the impact of artificial intelligence technology on the consumer and determining his behavior towards an advertisement for a specific commodity?

\section{Research Importance}

With the digital marketing revolution, it has become extremely important to deeply use the concept of artificial intelligence in media advertising campaigns because there is a large amount of data that can be used to improve these campaigns, which doubled their importance to reach innovative ideas and give a special character.

\section{Research Objectives}

The research aims to:

- Explaining the concept and development of artificial intelligence and its connection with media advertising campaigns.

- Questioning the role of the media advertising campaigns implemented using artificial intelligence in terms of influencing the audience, conveying the advertising message, and the sustainability of its success among the audience.

- Achieving the highest success rate and the highest benefit for companies from implementing media advertising campaigns using artificial intelligence. 


\section{Research Methodology:}

The research is based on the historical and descriptive methods.

\section{Research time period:}

2000-2020 AD

\section{Spatial boundaries:}

Available from all countries of the world

\section{Intelligence Definition}

The term intelligence, in Latin, means the ability to understand, but in the scientific arena, where there are many disciplines and branches, we find it difficult to find a unified definition of the term intelligence, and it is agreed upon by the academic researchers. The intelligence in the human brain on rum is often summarized by the presence of elementary creatures that can accomplish extremely complex tasks that do not have biological brains such as ants and bees.

\subsection{Intelligence Definition in Philosophy}

The concept of intelligence for philosophers was hostage to many fluctuations and changes over time, but the majority of them linked intelligence with the individual's ability to think, as the old concepts were very close to $\mathrm{k}$, contrary to the instinct that is more suitable for reactions than to thinking, but soon the concept changed and It developed with the advancement of ages and philosophers under the influence of scientific fields and other currents to prevail instinct as well.

British psychologist Cyril Burt defined intelligence as a general innate capacity for perception. David Wechsler stated that intelligence is the complete and complex ability of an individual to make an effort for a specific purpose and think rationally in response to the state of his surroundings in which he is. And before that, Plato gave "Plato", as he gave a short definition, but more mama in all the sciences, as he said that intelligence combines all kinds of mental pitfalls that an individual can attain. As for Aristotle, who lived as pre-Christ philosophers, he did not give a clear definition, but he classified intelligence as a distinct feature separate from decision and logic. Including tactical intelligence, experimental, theoretical, political and social intelligence.

Based on that, a unified summary within the framework of philosophy can be based on 4 pillars, which are:

- Gain ideas

- Save ideas

- Transferring ideas

- Transfer of ideas 


\subsection{Intelligence Definition in Psychology}

The concept of intelligence is closely related to psychology, since the earliest treatises linked it to the human brain and its behavior. We mention among them the Swiss psychologist Jean Piaget, who proved through his studies that intelligence is generated as a result of the individual's adaptation to his environment, and he distinguished between functional intelligence and studied intelligence, and in 1905 the French psychologist Alfred Binet developed what is called the thought quotient. "Intellectual Quotient", which is a mathematical outcome measure for comparing human intelligence, obtained through a series of tests in different fields such as logic, memory, deduction, etc.

\section{Artificial Intelligence Definition}

Before giving a specific concept to $\mathrm{Al}$, it should be noted that the basic principle on which $\mathrm{Al}$ is based does not lie in solving problems more quickly, in processing more data, or in preserving the largest number of information drawn from the human mind, but rather the correct principle on which this field was explained In fact, it is the principle of processing information, regardless of its nature and size, in an automatic or semi-automatic manner, in an appropriate manner and compatible with a specific goal. And we point out here that the word semi-automatic means human intervention in processing, and let us mention, for example, the smart semi-automatic systems specialized in piloting aircraft (Auto Pilot)

So, artificial intelligence is the scientific and technical current that includes methods, theories and technologies that aim to create machines capable of simulating intelligence. The specialists in mechanics and informatics consider that this definition is clear and familiar with their field, as explained by that. While others point out that this text is not clear as a complete definition due to its nature as a modern age science dependent on innovation, innovation and change.

But what everyone agrees on is that its primary role is based on searching for ways to solve problems of logical, mathematical and algorithmic complexity. Before the emergence of big data, which we will give an introduction to and its relationship with artificial intelligence. The ambition of artificial intelligence was content with imitating humans in certain applications of its cognitive functions, but with the witnessed acceleration and escalation of big data, the ambitions of this technology exceeded the limits of human imitation.

Artificial Intelligence consists of two concepts that are merged together although they are separated in theory:

- Memory: represented by storage, which is a form of intelligence also called negative intelligence

- Inference: It is the ability to analyze with an awareness of the relationships between objects and concepts in order to understand facts, and that is through the use of memory, logic and other means derived from mathematical sciences 


\section{The Reality \& Future of Artificial Intelligence}

The expectations of Al scientists predict that within the next ten years the machine will be able to perform $80 \%$ of the repetitive and difficult tasks, and in many cases it will have to make choices so that the matter of determining the ethical rules for machines becomes the most difficult task facing the human being, and in light of the big data, it will take a curve Quite another

There is no doubt that one of the biggest obstacles that hinder $\mathrm{Al}$ is defective data, which is the main problem in the learning and self-prediction characteristic, and it is one of the problems that have received the attention of the largest number of researchers in recent years in the sense that the learned algorithms need a large number of data to adjust their behavior in order to be more accurate. Therefore, with the sweep of abundant data and the entry of the era of big and condensed data, these algorithms have become more data-saturated, more accurate and more efficient, and a new stream appears under the shadow of artificial intelligence called Big Data, which is in fact a harmony between smart algorithms and big data. And here is the field of "Big Data Analytics", which is a branch of Al and is concerned with analyzing huge amounts of data and providing recommendations and assistance to users based on results

\subsection{Smart Marketing}

Thanks to digital marketing techniques, large stores today can predict about a pregnant woman's customer, and the march adjusts his sales to add materials that suit her position in order to increase his sales, such as clothes for pregnant women without more information about the month of pregnancy or the gender of the fetus. This type of purposeful marketing has been around and in use for a few years thanks to customer loyalty cards that store purchase history in this store. But with analytical big data, we pass into a new era of artificial intelligence, where the walker will be able to obtain more information about the gender of the child and the date of birth through the use of more data, which allows the marketing department to predict and know the newborns of the children of its customers and thus planning to increase sales Where more accuracy in forecasting means better planning and management of that.

\subsection{Augmented Reality}

Augmented reality is the overlapping of real live reality with other virtual elements such as $2 \mathrm{D}$ and $3 \mathrm{D}$ sounds and video clips in a consistent way. And it can go even further by adding motivational visualizations such as touch and audio effects. Even today, the field of video game development and the field of cinema has acquired this type of technology that has not yet developed to smart or automatically learned technologies, but today the applications that experts are working on. In research centers, it goes beyond that to an augmented reality with an intelligent virtual world that can develop quickly and directly by reading and digesting real data. And in this, the algorithms will be able to make 
INTERNATIONAL JOURNAL OF

ARTIFICIAL INTELLIGENCE AND EMERGING

TECHNOLOGY

automatic decisions automatically, and the first beneficiary will be industries such as design and maintenance, as well as the medical field such as detection and surgery.

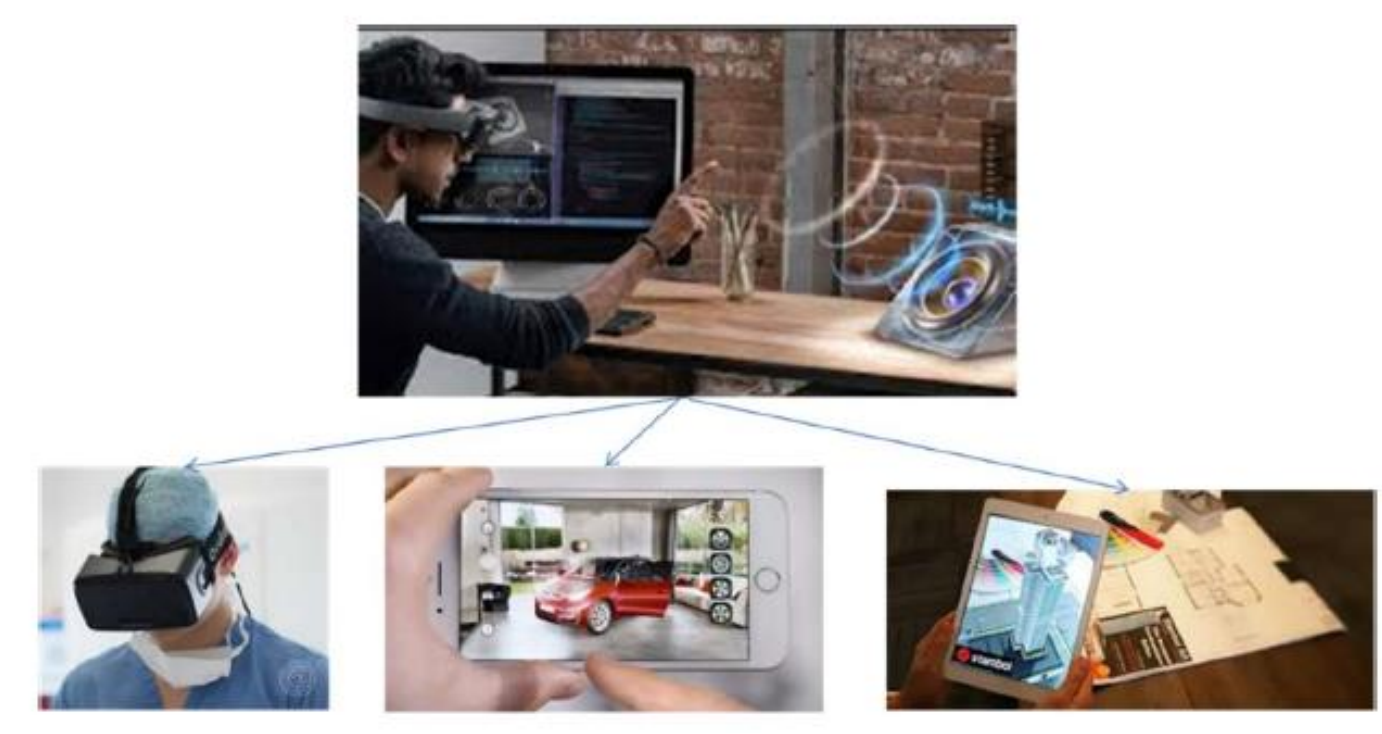

IMAGE(1)-SAMPLES OF AUGMENTED REALITY

ARTIFICIAL INTELLIGENCE BETWEEN REALITY AND EXPECTATIONS, A TECHNICAL AND FIELD STUDY, PP. 13 - PG. 17

(ARABIC VERSION)

\subsection{Analyzing Customer Behavior using Artificial Intelligence:}

Analyzing customer behavior using Al capabilities can save a significant amount of time, compared to human employees. All mistakes people could make will be eliminated. But this does not mean that data analysts have become useless. No, experts in this scenario will be used to perform more complex tasks, while machine intelligence will take over the routine tasks.

This is where artificial intelligence comes in. This technology has all the potential to change the way retailers interact with customers. In particular, Al can provide deep customer relationship management analytics and more valuable insights into customer behavior, expectations, tastes, and desires. If done right, Al can empower companies to be able to deliver the right products to the right customers when the time is right.

Unfortunately, companies invest in strategies and tools designed to engage with customer interactions. As a result of these methods, customers receive products and offers that are already slightly or entirely off-track from their current preferences and desires. No wonder it turns into lost opportunities, wasted resources, lack of return on investment, and lower income. 
Intelligent customer behavior analysis is the only thing that can change this scenario in 2020. Relying on guesswork is next to impossible to make an accurate prediction of a potential purchase, the success of a specific marketing campaign, or the ability to create unique and personalized customer experiences.

Artificial intelligence and machine learning are precisely what retailers and marketers need. Advances in these technologies allow content and products to be segmented for customers based on an analysis and understanding of their buying habits. But customization is not efficient enough. Retailers need solutions and tools that customize interactions with customers and increase brand loyalty.

Al can provide individual customer experiences by predicting how customer behavior will affect current business models, and help transform marketing campaigns.

\subsubsection{Ensure the appropriate message size for your target audience (Footasylum)}

Consumers are targeted with social messages from every platform, and your content might get lost in the noise. Artificial intelligence can study social media behavior to understand when a customer is ready to engage with your brand - or reduce communication during periods of low engagement.

Recently, UK-based Footasylum has implemented Al to segment its audience into targetable profiles. Then these profiles were used to create similar audiences on social media. The technology even recommended the right moment to share ad content, to increase conversion chances.

Footasylum has been able to generate an impressive return on advertiser spending (ROAS), as the smart combination of $\mathrm{Al}$, audience segmentation, and social media has enabled returns 30 times higher than the industry average.

\subsubsection{Personalize the audio track for your ad campaigns (Cox Communications)}

With the advancement of artificial intelligence technology by leaps and bounds, it is now possible to adjust the background sound for commercial ads using artificial intelligence. Marketers usually spend hours or even days producing the audio, but to no avail for the ad campaigns; But with video, your choice of backstops and supporting music can make all the difference in how customers perceive the brand.

The Al promises to cut production time, from days to just a few minutes. Advertising company Cox Communications is currently implementing an exciting pilot program in partnership with Spark Foundry.

In this experiment, each new ad unit will use Al to automatically generate creative audio elements. This will help the company expand rapidly across channels, maintaining a delicate balance between programming and customization. Thanks to the power of artificial intelligence, Cox Communications reduced ad production time from 2 days to 3 days to less than 10 minutes. 


\subsubsection{Connect with customers based on hidden behavior patterns (Nestle)}

Artificial intelligence doesn't just bring benefits in terms of effort and cost reduction. You can also unlock opportunities that would otherwise have been overlooked. Al can scan millions of data sets in a fraction of the time; It can shed light on prevailing patterns, and marketers can use these behavioral patterns to target their customers in new ways.

Nestle used artificial intelligence to scan popular songs and media in the public domain to uncover trends around food consumption. A surprising link emerged: There were at least 50 cases of ice cream linked to breakfast. Additional market research revealed that the sweet products are proving to be a popular breakfast ingredient in the United States.

Building on these insights, Nestlé launched its "Breakfast for Desert" line of products, which is quickly becoming an industry standard.

\subsection{Artificial Intelligence and facial recognition in developing advertising campaigns}

\subsubsection{Trying a new, custom look and ad format (Walgreens)}

If your fridge door screen changes from Pepsi to flavored water before your eyes the next time you walk into Walgreens, don't be surprised.

Walgreens rolls out a new technology that integrates cameras, sensors, and digital screens into its cooler doors, creating smart screens that target ads for individual customers. The sensors and cameras connect to face detection technology that can determine the age and gender of a customer, as well as external factors such as whether it is hot or raining outside and how long you stand there, and even capture your emotional reaction to what you are looking at.

This allows Alawab to function as a dynamic and responsive marketplace, similar to how online advertisements use your information to more effectively advertise your interests.

Doors have many benefits, such as real-time stock information and instant campaign feedback, but they also raise questions about the future of target marketing and where the sneak streak exists in this modern market. 


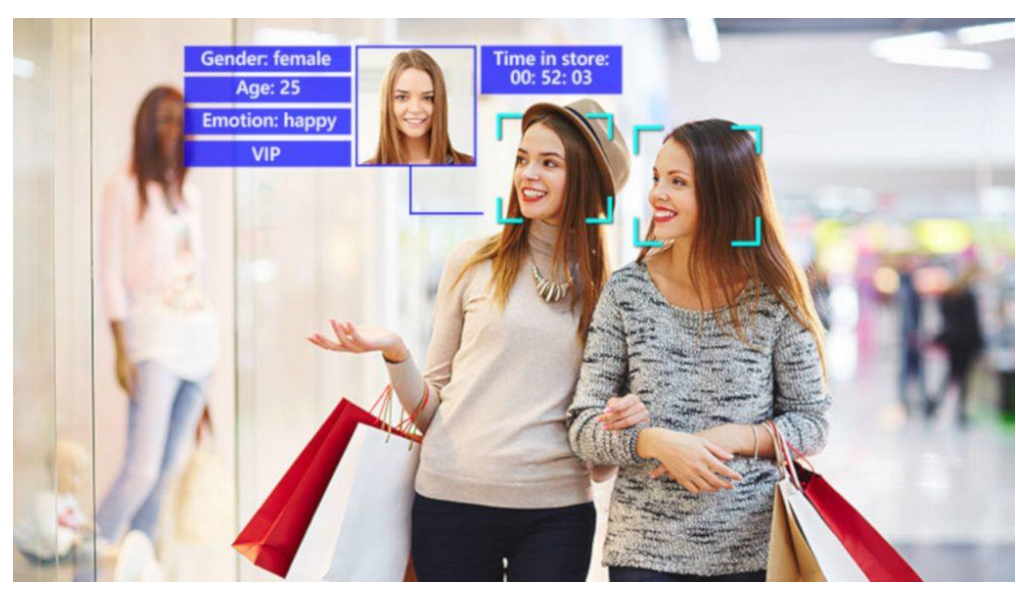

IMAGE (2) - THE USE OF ARTIFICIAL INTELLIGENCE TO KNOW THE PERSON'S DATA IN ORDER TO TARGET HIM WITH CORRECT ADVERTISING

\section{HTTPS://GIGASOURCE.IO/FACIAL-RECOGNITION-IN-RETAIL-STORES/}

\subsubsection{Facial recognition in retail - enhancing the customer experience in store}

Retail stores are now centers of expertise and then mere outlets. To provide a connected and engaging in-store experience, retailers are constantly integrating innovative technologies. A couple of examples define campaign effectiveness through behavioral analyzes of the face using an Al-enabled camera on digital signage, sending personalized promotions on mobile devices by discovering a customer's location in the store, using interactive kiosks and digital displays to browse the entire product catalog. Moreover, the face recognition feature has raised shopper identity to a whole new level with advancements in artificial intelligence technologies

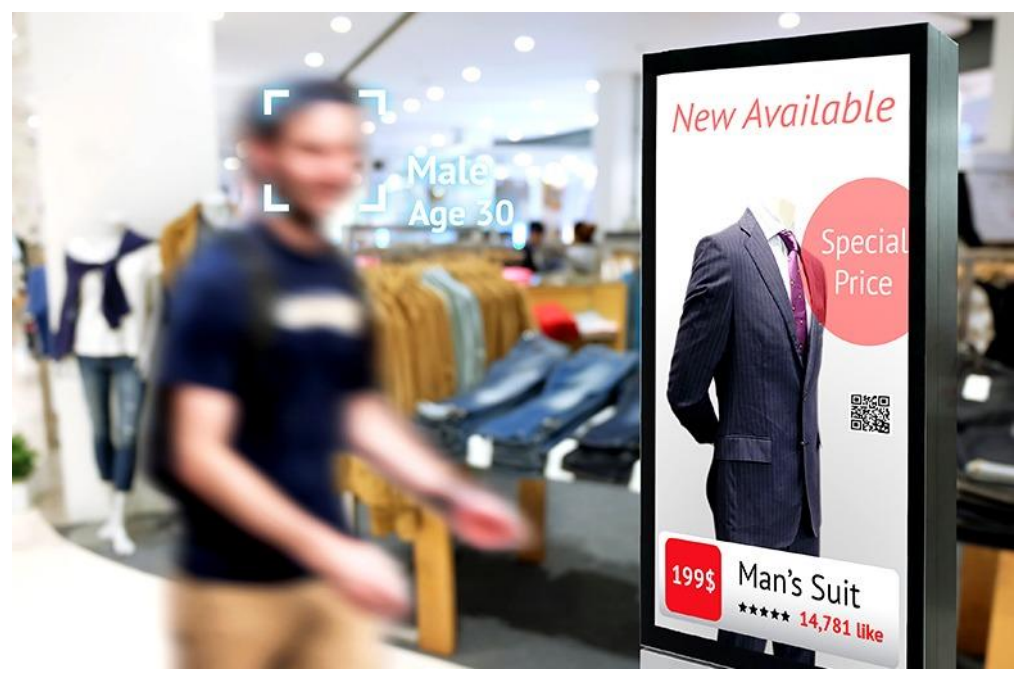


INTERNATIONAL JOURNAL OF

ARTIFICIAL INTELLIGENCE AND EMERGING

TECHNOLOGY

IMAGE (3) - AFTER KNOWING THAT THE PERSON IS MALE AND HIS AGE, THE ADVERTISING SCREEN CHANGES TO SHOW HIM THE SUIT ADVERTISEMENT

HTTPS://WWW.VIATECH.COM/EN/2018/08/FACIAL-RECOGNITION-SMARTER-STORES/

\subsubsection{Douwe Egberts}

South African coffee company Douwe Egberts also came up with a targeted marketing idea using facial recognition technology. The company set up a coffee machine at O.R. Tambo International Airport. As a free promotional offer, the coffee machine used facial recognition technology to detect when travelers yawn while they were passing by. Those who yawned immediately got a cup of coffee from the vending machine

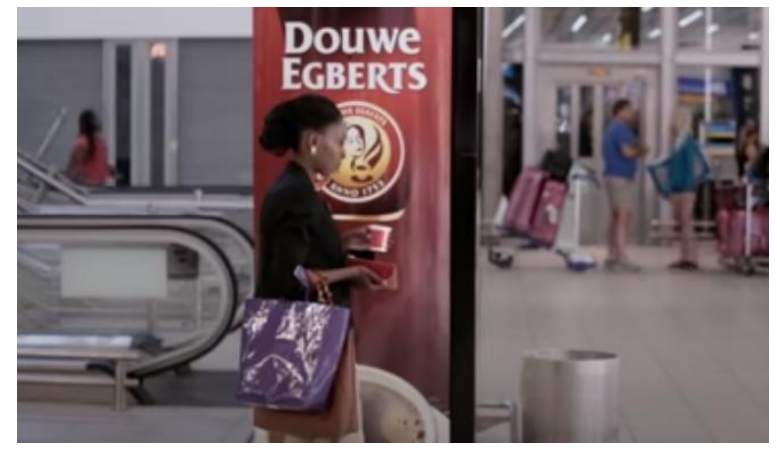

IMAGE (5) - THE COFFEE COME OUT OF THE MACHINE WHEN IT RECOGNIZES THAT A PERSON IS FEELING SOFT

HTTPS://YOUTU.BE/HOTQ8ZOFQHO

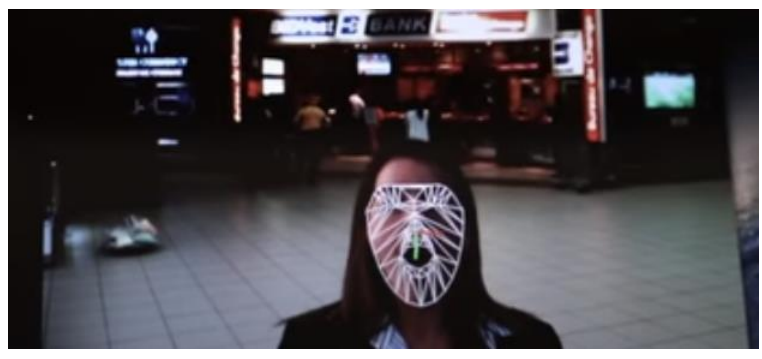

IMAGE (4)- THE MACHINE RECOGNIZES THE FACE AND KNOWS IF A PERSON FEELS SLEEPY THROUGH MOUTH MOVEMENT AND RED EYE COLOR HTTPS://YOUTU.BE/HOTQ8ZOFQHO

\subsection{Smart chatbots in developing advertising campaigns}

Smart chatbots can be found among the contemporary technological innovations for communicating with customers. Substantial advances in technology, the widespread use of mobile devices and applications, and the latest developments in artificial intelligence and machine learning have led to an increase in interest in chatbots. The word "chatbot" consists of the words "chat" and "robot" and is defined as a computer program that enacts a human language with the help of a textual dialogue system. Chatbots include an identity to hide text input and output, allowing users to contact the software behind them and make the impression of chatting with a real individual. In these discussion-like interfaces that are fueled with natural language data, the intelligent system learns to automatically suggest responses to stakeholders in a text format based on historical customer interaction.

Chatbots depict a potential shift in how individuals communicate with online services. Since the introduction of smartphones and mobile device applications, chatbots are mostly used for messaging 
applications rather than computer programs. A closer look will be taken at the use of chatbots on social media.

Marketing strategy robots can be useful in activities carried out in the social media space while suggesting specific contents or a way to interpret and understand reality. Their personality, generally understood as their way of conducting conversations, style of behavior, form and set of global phrases and sayings used, etc., can intensify consumer experiences and emotions desired by the company / brand while influencing purchasing decisions and market behavior. A well-prepared chatbot with a charming personality that will efficiently guide the buyer through the later stages of transactions while saving their cognitive effort and time, may become a core value that differentiates a particular brand from its competitors. It's definitely more social, friendly, and realistic than current market apps, especially with the way he establishes a connection, has a conversation, or tries to build a relationship.
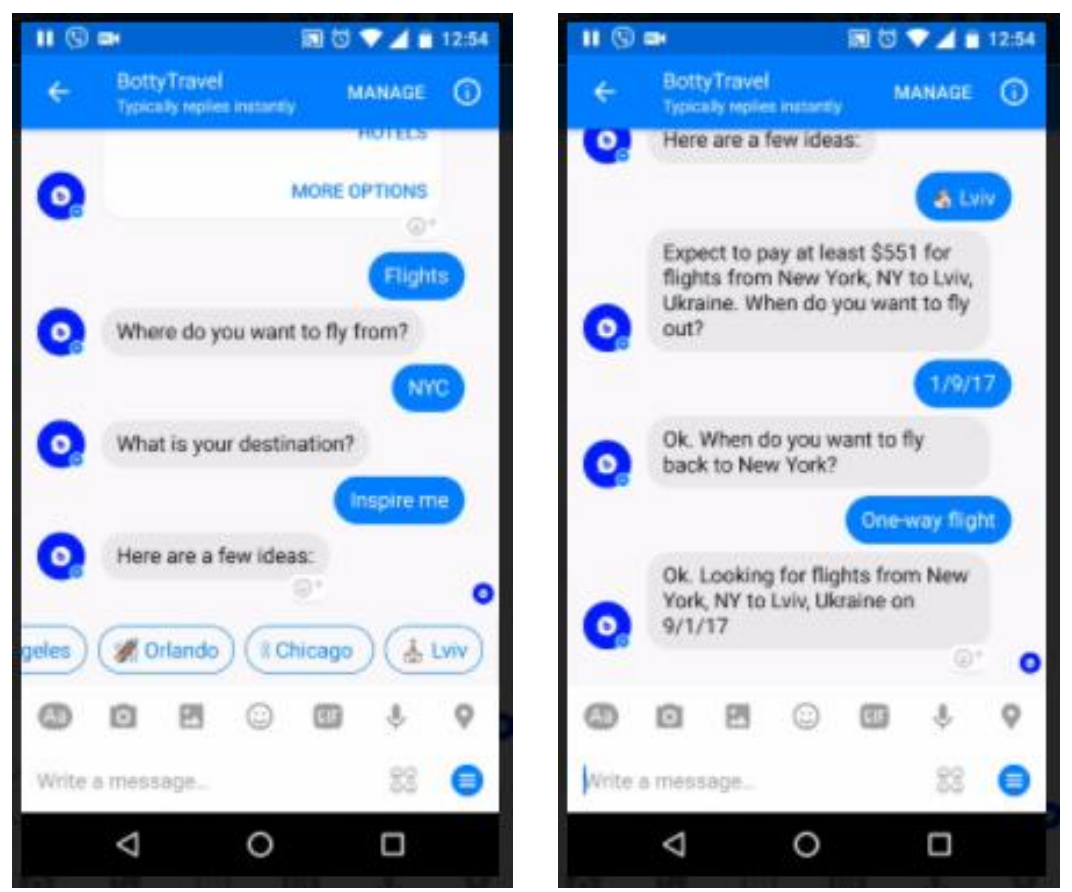

IMAGE (6) -- A CONVERSATION APPEARS WITH A SMART CHATBOT THAT SUGGESTS TRAVEL DESTINATIONS

HTTPS://BOTSCREW.COM/BLOG/FACEBOOK-ADS-CHATBOTS/

\section{Facts and statistics for the use of artificial intelligence in advertising advertising}

- $51 \%$ of marketers use at least some form of artificial intelligence

- Experts believe that artificial intelligence will create 2.3 million new jobs

- Al will handle $85 \%$ of customer service inquiries by 2021 
- 3 out of 4 companies applying $\mathrm{Al}$ in marketing have achieved a $10 \%$ or more increase in sales

- By $2021,30 \%$ of companies will be using $\mathrm{Al}$ in at least one of their advertising operations

- $35 \%$ of customers are happy with the chatbot

- $75 \%$ of organizations say that the use of Al has helped increase customer satisfaction by at least $10 \%$

- Businesses that use $\mathrm{Al}$ to support data-driven insights in marketing will grow to $\$ 1.2$ trillion by 2022

\section{Models for companies that used artificial intelligence in advertising}

\subsection{Starbucks Corporation uses predictive analytics to provide personalized recommendations}

Starbucks is one example of a brand using a loyalty card and mobile app to collect and analyze customer data. They announced plans to privatize again in 2016.

Since then, they have created the perfect app experience. Records details of purchases, including where they were made and at what time of day. Starbucks uses predictive analytics to process this data and serve customers with personalized marketing messages. These messages include recommendations when approaching a local store as well as offers aimed at increasing the average value of a customer's order.

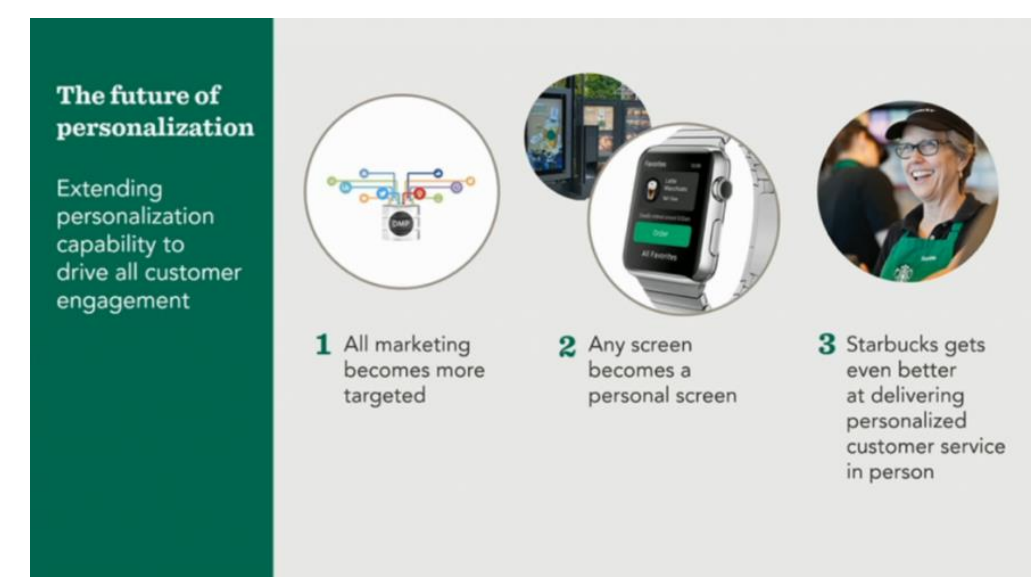

IMAGE(7)- STARBUCKS USING ARTIFICIAL INTELLIGENCE

HTTPS://BLOG.SOCIALMEDIASTRATEGIESSUMMIT.COM/10-EXAMPLES-OF-AI-IN-MARKETING/

\subsection{Clients Create Custom Nikes In 90 Minutes}

In 2017, Nike launched a system that allowed customers to design their own sneakers in store. The Nike Makers Experience lets customers wear blank Nike Presto $X$ shoes and choose their own graphics 
INTERNATIONAL JOURNAL OF

ARTIFICIAL INTELLIGENCE AND EMERGING

\section{TECHNOLOGY}

and colors. Using augmented reality and display systems, the system then projects the design onto the empty shoes. The designs are printed on the sneakers and available to the customer in about 90 minutes.

This customer engagement feature not only increases sales, but more importantly, it allows the sneaker brand to collect data about customer preferences. Nike then used this data with machine learning algorithms to design future products and provide personalized product recommendations and marketing messages.
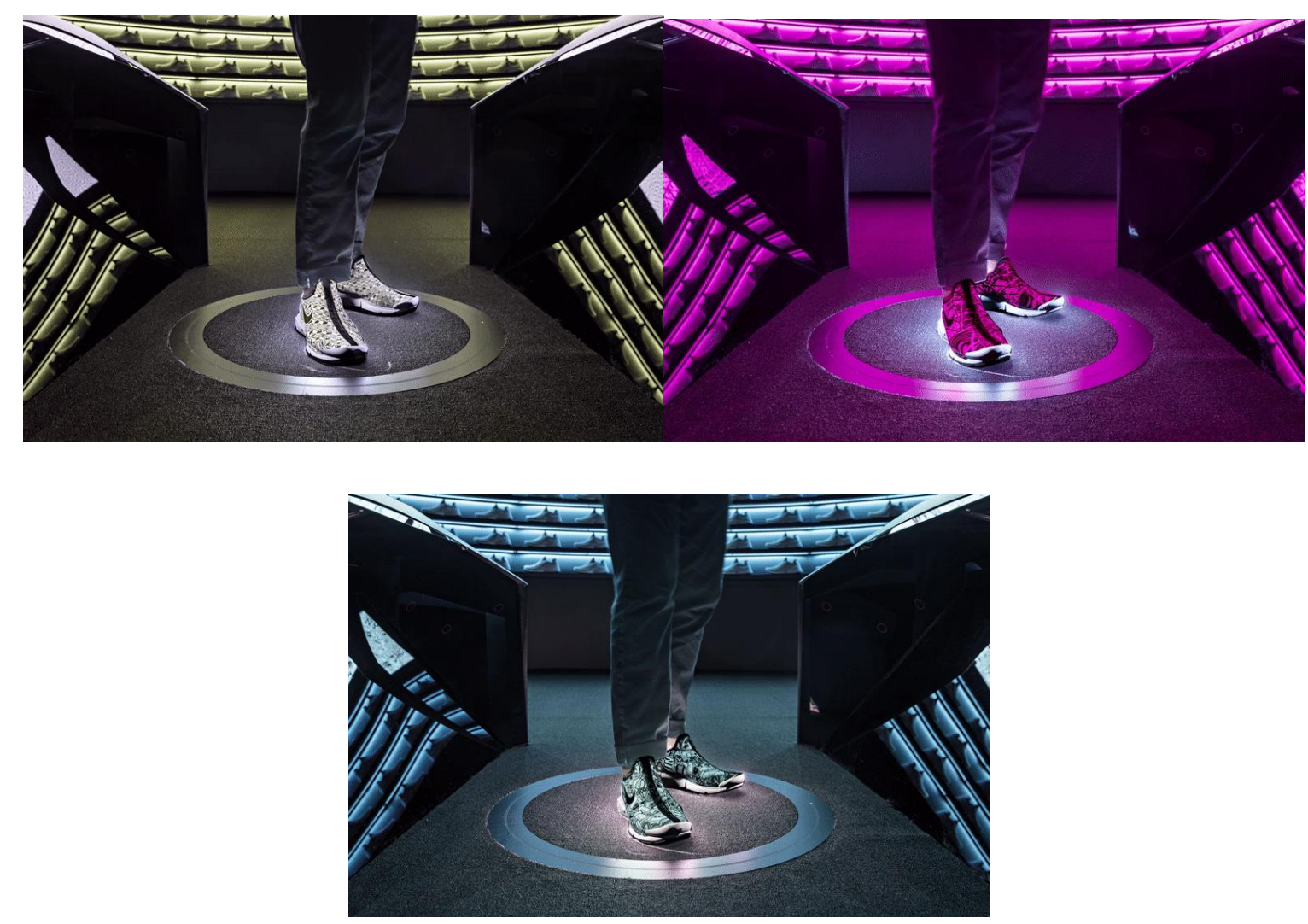

IMAGE (8) - NIKE USING ARTIFICIAL INTELLIGENCE

\section{-HTTPS://BLOG.SOCIALMEDIASTRATEGIESSUMMIT.COM/10-EXAMPLES-OF-Al-IN-MARKETING/}

\subsection{Sephora chatbots}

Sephora chatbot has helped consumers narrow their choices, starting with testing around their product preferences. This has been particularly beneficial in the cosmetic industry, where the options can be overwhelming and difficult to purchase without personally testing the product. Sephora has gained valuable insights from its chatbot and has seen enough engagement from that experience that it has since launched more messenger chatbots. 


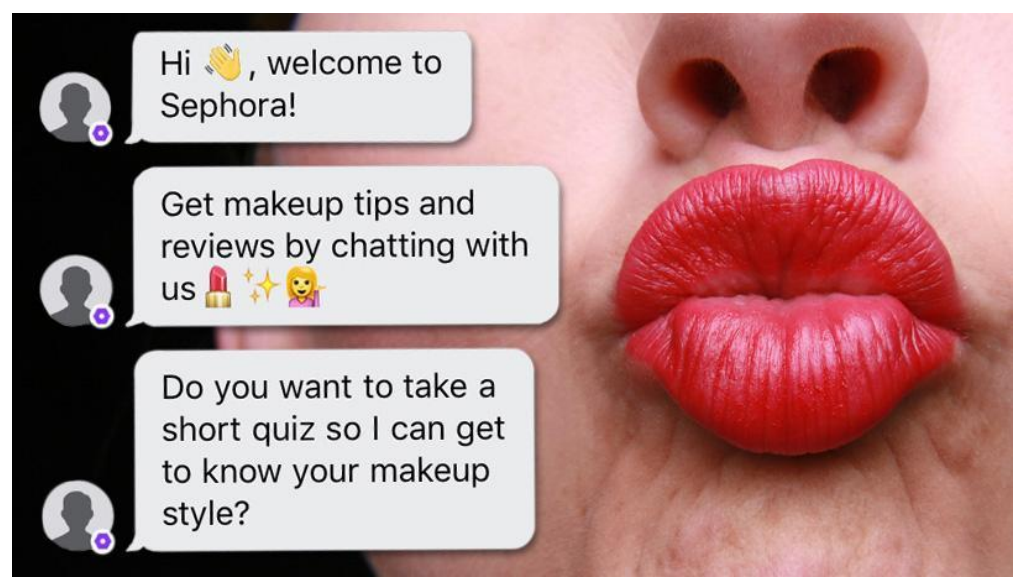

IMAGE (9) - USING SEPHORA AI CHATBOT IN MAKEUPS ADVERTISING CAMPAIGNS

HTTPS://BLOG.SOCIALMEDIASTRATEGIESSUMMIT.COM/10-EXAMPLES-OF-AI-IN-MARKETING/

\subsection{Nutella Use Artificial Intelligence in Design}

Artificial intelligence is able to help designers create millions of unique products and unique versions of packaging designs while maintaining brand style and design integrity. For example, in 2017 Ferrero partnered with media agency Ogilvy \& Mather Italia to increase their sales and get more people to buy Nutella. Their plan was to have an algorithm for designing a packaging shell. The algorithm was loaded with patterns and colors from the database to create seven million unique packaging wrappers that were sold all over Italy within a month.

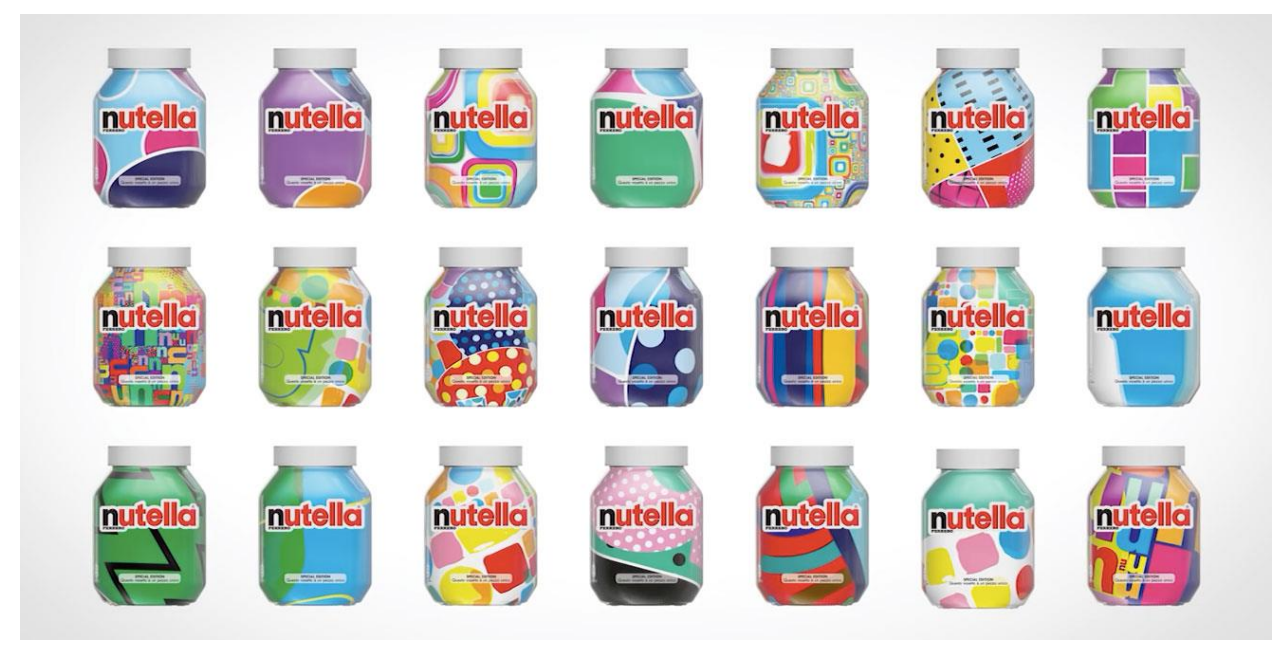

\section{IMAGE (10) - NUTELLA EXPERIMENT IN DESIGNING 7 MILLION DIFFERENT DESIGNS AND NUTELLA ID FOR MARKETING USE}

Creating multi-shaped and color graphic assets is also one of the tedious parts of a designer's job. Artificial intelligence can help by providing algorithms to do simple tasks like color matching. For example Yandex.Launcher uses an algorithm to automatically setup colors for app cards based on app 
icons. Other variables can also be set automatically, such as changing the text color according to the background color and other features

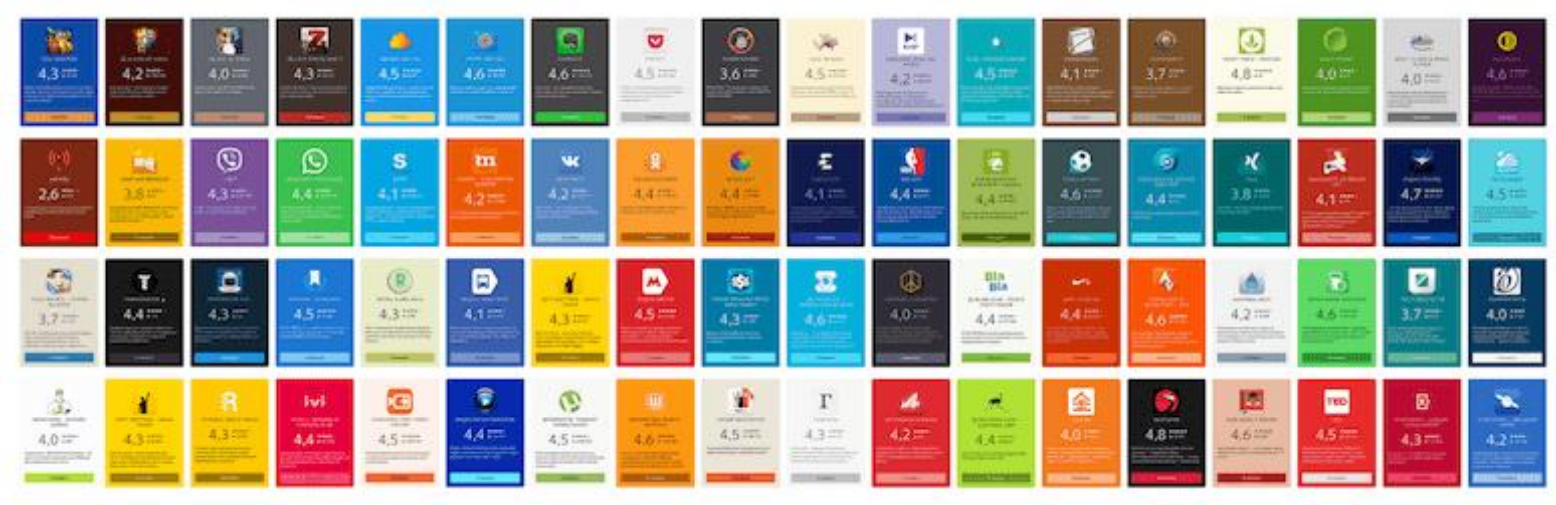

IMAGE (11) - YANDEX.LAUNCHER LENDS THE APP'S THEME AND COLOR BASED ON ITS ICON

\section{Conclusion}

\section{Recommendations / content regulation}

With analytics and forecasting, organizations can provide better recommendations to their users, allowing them to get the most out of their subscriptions. This results in greater customer satisfaction and increased value proposition.

\section{Automated advertising}

When it comes to ad targeting, showing the right ads to the right customer at the right time is a challenge for companies like Google Ads to sell ad inventory. However, by incorporating artificial intelligence technologies such as programmatic advertising, Google has been able to complete the process of buying and selling ad inventory using the power of artificial intelligence.

\section{Customer behavior}

This Al technology effectively analyzes visitor behavior and enables real-time campaign optimization for the likely converting audience.

According to Seer Interactive (interactive prediction), Al technology uses its algorithms to analyze visitor behavior, allowing for immediate campaign improvements toward that specific user. This means that depending on what the consumer likes, dislikes, and habits, the program can evaluate a search and then immediately select ads to purchase and display within milliseconds.

\section{Image recognition}


From a marketing standpoint, image recognition may mean better synchronization between online content and store visits. Many stores use facial recognition software to track customer visits in the store and link these videos to their customers' profiles. Up to $59 \%$ of UK fashion sellers deploy facial recognition software in their stores. When combined with Al notifications, stores can send both realtime discount offers and welcome messages to visitors.

\section{References}

- History of Artificial Intelligence, Prof. Dr. Hussam Hassan Muhammad Ismail, pp. 3-p. 6 (Arabic Edition)

- Artificial Intelligence between Reality and Expectations, a technical and field study, pp. 13 - pg. 17 (Arabic Edition)

- How chatbots influence marketing, DOMINIKA KACZOROWSKA, p250 - p 255

- The application of chatbots in Digital Marketing Communications and their effect on consumer behavior, thesis, Sunderland Business School, Paraskevi Tzani, P25 - p28

- HTTPS://WWW.MARTECHADVISOR.COM/ARTICLES/MACHINE-LEARNING-AI/5EXAMPLES-OF-AI-IN-MARKETING-IN-2019\#/ 5/2/2021-8:00 pm

- HTTPS://WWW.EINFOCHIPS.COM/BLOG/FACIAL-RECOGNITION-IN-RETAIL-ENHANCEIN-STORE-CUSTOMER-EXPERIENCE-AND-IMPROVE-RETAILER-OPERATIONS/ 4/2/2021 - 12:30 AM

- https://blog.socialmediastrategiessummit.com/10-examples-of-ai-in-marketing/ 5/2/2021 10:30 PM

Received: April 2021

Accepted: June 2021 